\title{
La rebelión pingüina: un caso de épica vicaria
}

\section{María de los Ángeles Fernández R. ${ }^{1}$}

Ad portas del tercer aniversario de la llamada "revolución pingüina," movilización de estudiantes secundarios que partió con la protesta por el costo del pase escolar y la Prueba de Selección Universitaria y desembocó en un debate que puso el dedo en la llaga de la deficiente calidad e inequidad de la educación chilena, y cuando el país empieza lentamente a contagiarse por las dinámicas propias de la próxima campaña presidencial, pareciera necesario interrogarse por el real carácter de este fenómeno y su posible impacto, no tanto en las dinámicas intrínsecas al sistema educativo que buscó remecer, sino en otro de los aspectos que develó este suceso: la inexistencia de vehículos de expresión de las demandas ciudadanas, incluidas las de los sectores juveniles, más allá de los eventos electorales. Es ésta una deuda que arrastra nuestra transición política, un tanto oscurecida por los excelentes resultados que Chile obtiene en los rankings regionales de gobernabilidad política aunque, por suerte, nuevas formas de medición están comenzando a dar cuenta de este vacío.

La movilización de los estudiantes secundarios se manifestó como una implosión en un momento en que el país parecía sumido en un estado cercano a la parusía, celebrando la llegada de la primera mujer a la Presidencia. Este suceso no sólo concitó interés, alegría especial entre las mujeres y novedad a nivel nacional, sino también fuera de nuestras fronteras: no sólo porque resulta todavía una extrañeza que una mujer logre llegar a dirigir un país, sino que además lo haga por la vía de la competencia electoral. En América Latina las primeras mujeres Presidentas llegaron, casi siempre por la vía sucesoria, a reemplazar a un marido y en períodos de accidentabilidad política. En este marco, los jóvenes y sus demandas educativas irrumpieron en la escena pública rompiendo mitos, en un país aletargado salvo por sacudidas producidas, de manera espasmódica, por alguna que otra movilización sectorial que no logra esconder sus 
lógicas corporativas. Frente a la idea dominante de que los jóvenes adscriben a patrones individualistas, reniegan de la política y son reactivos, impacientes y consumistas, se produjo un fenómenos que era su antítesis: jóvenes organizados, con capacidad de articulación y de adhesión, elaborando planteamientos que si bien se dirigían a aspectos concretos de la experiencia educativa, terminaron por interpelar a la estructura del sistema educativo y, en definitiva, al modelo de organización de la sociedad como un todo.

Si bien es cada vez más difícil para quienes conducen los países anticipar las situaciones que se producen en sociedades complejas, cabe preguntarse cómo las autoridades fueron sorprendidas de tal forma por esta movilización al punto que el programa de campaña de Michelle Bachelet incluía apenas doce líneas en lo relativo a la educación secundaria, con un discurso centrado en la necesidad de desarrollar competencias. Si bien es cierto que las exigencias globales de un programa de gobierno, que debe hacer diagnósticos y propuestas para todos los aspectos de la vida en sociedad, no pueden evitar la generalidad y el sentido común, también es cierto que la ausencia de postulados más específicos relacionados con las demandas que los jóvenes plantearon, a dos meses de haber asumido el gobierno, constituyen una evidencia de lo que se ha venido a denominar la brecha entre la ciudadanía y la élite política. Un cínico político no trepidaría en señalar que no hay que extrañarse, por cuanto los programas de gobierno están para no ser cumplidos. Sin embargo, la distancia que reveló este suceso debiera alertar a los futuros candidatos presidenciales y a sus equipos de campaña, no sea cosa que terminen enfrentando sinsabores parecidos. La pregunta es si se podría haber esperado otra cosa por cuanto uno de los aspectos más llamativos del proceso político chileno, y que pudieran resultan comprensibles en los primeros años de la transición, pero menos aceptables ahora es, según DíazTendero ${ }^{2}$ "el carácter notoriamente cupular, limitado a núcleos pequeños de dirigentes que actuaban con considerable libertad en un entorno de fuerte respaldo de adherentes y simpatizantes." El protagonismo excesivo de la "técnica" en casi todos los procesos durante estos años ha puesto de manifiesto de manera dramática sus limitaciones y miopías con la puesta en marcha del plan de transporte capitalino Transantiago pero ya la movilización 
pingüina fue un preludio, un anticipo, de los riesgos que entraña la exclusión de mecanismos y espacios que permitan acoger la subjetividad de los distintos actores sociales.

La inexistencia de puentes se confirma con cifras de informes de reconocida seriedad que vienen dando cuenta de los déficits que la democracia chilena enfrenta en materia de representación e inclusividad. Una primera señal de alarma la dio la revista The Economist, ${ }^{3}$ que realizó un ranking denominado "El mundo en 2007." En dicho estudio, nuestro país fue considerado como el segundo país dentro de las democracias imperfectas, ubicándolo en el lugar número 30 a nivel mundial y tercero a nivel latinoamericano. En participación política, nuestro país obtuvo sólo un puntaje de 5,00, lo que nos dejó en último lugar. Otro ranking tan reconocido como el del Banco Mundial constata que "se habría producido una caída apreciable durante los primeros dos años de gobierno de la Presidenta Bachelet en lo que dice relación con estabilidad política y voz y accountability. Para estos indicadores, Chile bajó alrededor de 10 percentiles (del 75 al 66 para el primero y del 88 al 77 para el segundo). Estos indicadores son los más relacionados con la calidad de la política. En el caso de la estabilidad política, esto es evidente ya que para voz y accountability se mide, entre otros, en qué medida los ciudadanos pueden participar eligiendo a sus gobernantes." ${ }^{4}$ Por su parte, el más reciente Latinobarómetro, correspondiente a 2008, señala que "si bien Chile aparece en primer lugar como la democracia que funciona mejor comparada con la región, al mismo tiempo, tiene una visión muy crítica de su propia democracia, con altas demandas." Sólo el 23\% dice que se gobierna para todo el pueblo y, en la medición sobre participación política, Chile es el país con el número más bajo de la región, 3\% frente a un promedio de la región que es $11 \%$.

Las condiciones para la expresión y participación ciudadana no han experimentado cambios después de la movilización pingüina aunque se ha aprobado en el Congreso recientemente la inscripción automática y el voto voluntario. Sin embargo, nadie puede apostar al día de hoy si se podrá operacionalizar para las elecciones de fin de año. Mientras tanto, algunos de los líderes pingüinos se han integrado a partidos políticos tradicionales $\mathrm{y}$, por estos días, ejercitan el cortesano ejercicio de fotografiarse con posibles candidatos presidenciales. Por otra parte, la prensa viene 
advirtiendo que son tantas las indicaciones presentadas a la Ley General de Educación (LGE), que la aprobación de la norma se ve cada vez más lejana.

¿Significa esto que fue una rebelión inútil, investida a lo sumo de un halo de romanticismo?, ¿qué los análisis realizados sobre este fenómeno, no sólo pecaron de anticipación sino que fueron un tanto apologéticos? Una visión más matizada diría que debiéramos dar gracias a los jóvenes pingüinos, independientemente de los resultados concretos de su lucha: lograron inyectarle épica a nuestras vidas, desafiando la fatalidad y sustituyendo el ambiente de desencanto que rodea las circunstancias personales de muchos adultos que se sienten amordazados por las jaulas del mercado, de la tecnología y de la burocracia. Por un momento, lograron contagiar a todo el país de la legitimidad de su lucha, haciéndonos sentir desde nuestros respectivos roles de estudiante, profesor y apoderado y aunque fuera por un rato, que somos parte de una comunidad política.

\section{Notas}

1 Directora Ejecutiva, Fundación Chile 21. Ex presidenta de la Asociación Chilena de Ciencia Política (2000-2002).

2 Para más detalles, consulta Díaz-Tendero, Eolo. "Iluminismo democrático "versus" ciudadanía sectorial." En $\mathrm{La}$ "izquierda" en América Latina, Editor Pedro Pérez Herrero. Madrid: Editorial Pablo Iglesias, pp. 83-113, 2006.

3 Citado en el artículo "Democracia chilena es imperfecta y se ubica en lugar 30 de ranking mundial," Diario Financiero, 22 de noviembre de 2006, p. 37.

4 Engel, Eduardo. "Es la política, estúpido," publicado en La Tercera Reportajes, 29 de junio de 2008, p. 26. 